\title{
Differential Expression of Tyrosine Hydroxylase Protein and Apoptosis-Related Genes in Differentiated and Undifferentiated SH-SY5Y Neuroblastoma Cells Treated with MPP ${ }^{+}$
}

\author{
Kawinthra Khwanraj, ${ }^{1}$ Chareerut Phruksaniyom, ${ }^{1,2}$ \\ Suriyat Madlah, ${ }^{1}$ and Permphan Dharmasaroja ${ }^{1}$ \\ ${ }^{1}$ Department of Anatomy, Faculty of Science, Mahidol University, Bangkok 10400, Thailand \\ ${ }^{2}$ Department of Pharmacology, Faculty of Dentistry, Mahidol University, Bangkok 10400, Thailand \\ Correspondence should be addressed to Permphan Dharmasaroja; permphan.dha@mahidol.ac.th
}

Received 8 September 2015; Revised 20 October 2015; Accepted 25 October 2015

Academic Editor: Mohammed Rachidi

Copyright (C) 2015 Kawinthra Khwanraj et al. This is an open access article distributed under the Creative Commons Attribution License, which permits unrestricted use, distribution, and reproduction in any medium, provided the original work is properly cited.

\begin{abstract}
The human neuroblastoma SH-SY5Y cell line has been used as a dopaminergic cell model for Parkinson's disease research. Whether undifferentiated or differentiated SH-SY5Y cells are more suitable remains controversial. This study aims to evaluate the expression of apoptosis-related mRNAs activated by $\mathrm{MPP}^{+}$and evaluate the differential expression of tyrosine hydroxylase (TH) in undifferentiated and retinoic acid- (RA-) induced differentiated cells. The western blot results showed a gradual decrease in TH in undifferentiated cells and a gradual increase in TH in differentiated cells from days 4 to 10 after cell plating. Immunostaining revealed a gradual increase in TH along with neuritic outgrowth in differentiated cells on days 4 and 7 of RA treatment. For the study on cell susceptibility to $\mathrm{MPP}^{+}$and the expression of apoptosis-related genes, MTT assay showed a decrease in cell viability to approximately $50 \%$ requiring 500 and $1000 \mu \mathrm{M}$ of $\mathrm{MPP}^{+}$for undifferentiated and RA-differentiated cells, respectively. Using realtime RT-PCR, treatment with $500 \mu \mathrm{M} \mathrm{MPP}^{+}$led to significant increases in the Bax/Bcl-2 ratio, p53, and caspase- 3 in undifferentiated cells but was without significance in differentiated cells. In conclusion, differentiated cells may be more suitable, and the shorter duration of RA differentiation may make the SH-SY5Y cell model more accessible.
\end{abstract}

\section{Introduction}

The well-established human neuroblastoma SH-SY5Y cell line has been used extensively to study dopaminergic neuronlike behavior in response to toxins in research on Parkinson's disease (PD) and neurotoxicity. Upon stimulation, proliferating SH-SY5Y cells can be differentiated into nonproliferating neuronal cells. Retinoic acid (RA) is a common inducing agent used to induce SH-SY5Y cells to become neurons of a dopaminergic phenotype [1]. Both undifferentiated and RA-differentiated SH-SY5Y cells have been widely used as a cellular model of PD. Controversy exists regarding which type of SH-SY5Y cells is most suitable for use in PD research. When exposed to neurotoxins, such as 1-methyl4-phenyl-pyridinium ion $\left(\mathrm{MPP}^{+}\right)$and 6-hydroxydopamine (6-OHDA), RA-differentiated cells expressed higher tolerance as shown by the lower rate of the release of lactate dehydrogenase (LDH), cell mortality, and caspase-3 activation, compared to undifferentiated cells, suggesting that undifferentiated cells are more appropriate for studying neurotoxicity or neuroprotection in experimental PD research [2]. In contrast, another study showed that SH-SY5Y cells become significantly more sensitive to 6-OHDA toxicity during the differentiation process as shown by cell mortality assay and $\mathrm{GI}_{50}$ values of 6-OHDA, suggesting that RAdifferentiated cells represent a more suitable experimental model for studying the pathophysiology of PD [3].

$\mathrm{MPP}^{+}$, an inhibitor of mitochondrial complex I, has been widely used as a neurotoxin because it elicits a severe PDlike syndrome. MPP ${ }^{+}$induces SH-SY5Y cell death through apoptosis. Treatment of undifferentiated and differentiated SH-SY5Y cells with $\mathrm{MPP}^{+}$causes the loss of cell viability, and condensation and fragmentation of nuclei, which is associated with the elevation of the reactive oxygen species (ROS) 
levels, an increase in the $\mathrm{Bax} / \mathrm{Bcl}-2$ ratio, and the activation of caspase-3 [4-11]. $\mathrm{MPP}^{+}$also activates the expression of the p53 tumor suppressor in SH-SY5Y cells [11-13]. In addition to its role in mediating a variety of antiproliferative processes in tumors, p53 can directly control transcription of proapoptotic members of the Bcl-2 family, such as Bax, with the net effect of increasing the ratio of pro- to antiapoptotic $\mathrm{Bcl}-2$ proteins, thereby favoring caspase activation [14].

Apoptosis is a genetically controlled process. The aim of this study is to evaluate possible differences in the expression levels of apoptosis-related mRNAs (p53, Bax, Bcl-2, and caspase-3) activated by $\mathrm{MPP}^{+}$using real-time quantitative RT-PCR analysis and evaluate the differential expression of a specific dopaminergic marker tyrosine hydroxylase (TH) in undifferentiated and RA-differentiated SH-SY5Y cells, for the assessment of suitable and accessible dopaminergic cell models for PD research.

\section{Materials and Methods}

2.1. Cell Culture. SH-SY5Y human neuroblastoma cells were grown in 1:1 mixture of MEM and F12, supplemented with $10 \%$ heat-inactivated fetal bovine serum (FBS), $1 \mathrm{mM}$ sodium pyruvate, $0.1 \mathrm{mM}$ nonessential amino acid, $1.5 \mathrm{~g} / \mathrm{L}$ sodium bicarbonate, 100 units $/ \mathrm{mL}$ penicillin, and $100 \mu \mathrm{g} / \mathrm{mL}$ streptomycin. All media and supplements were purchased from Gibco (Gaithersburg, MD, USA). Cells were maintained at $37^{\circ} \mathrm{C}$ in a humidified atmosphere of $5 \% \mathrm{CO}_{2}$. Cells were separated into two groups: undifferentiated and differentiated cells. For neuronal differentiation of SH-SY5Y cells, all-transRA was added a day after plating at final concentration $10 \mu \mathrm{M}$ in MEM-F12 with $10 \%$ FBS and maintained for 3 days. For $\mathrm{MPP}^{+}$susceptibility experiment, undifferentiated and differentiated SH-SY5Y cells were plated at the same time and exposed to $125,250,500,1000$, and $2000 \mu \mathrm{M}$ of $\mathrm{MPP}^{+}$for 24 hours. The control groups for undifferentiated and differentiated SH-SY5Y cells were treated with the same medium without $\mathrm{MPP}^{+}$.

2.2. MTT Assay. SH-SY5Y cells were seeded onto a 96well plate at a density of $1 \times 10^{4}$ cells/well in $200 \mu \mathrm{L}$ of medium and incubated at $37^{\circ} \mathrm{C}$ under $5 \% \mathrm{CO}_{2}$. Cell viability was measured by MTT (3-(4,5-dimethylthiazol-2-yl)-2,5diphenyltetrazolium bromide) colorimetric assay (SigmaAldrich, St. Louis, MO, USA). After incubation, $20 \mu \mathrm{L}$ of MTT $(5 \mathrm{mg} / \mathrm{mL})$ was added to each well and the cells were cultured for another 4 hours; then medium was removed and $100 \mu \mathrm{L}$ of DMSO was added to each well to dissolve the formazan. The color reaction, generated by the reduction of tetra ring of MTT by mitochondrial dehydrogenases with NADH in the active mitochondria, was measured spectrophotometrically at wavelength $570 \mathrm{~nm}$ with a reference at $665 \mathrm{~nm}$ using the VERSAmax Tunable microplate reader with SoftMax Pro software (Molecular Devices, Sunnyvale, CA, USA).

2.3. Western Blot Analysis for Tyrosine Hydroxylase. SHSY5Y cells were grown on 6-well culture plates at a density of $2.5 \times 10^{4}$ cells/well. After 24 hours, cells were treated with $10 \mu \mathrm{M}$ of $\mathrm{RA}$ in the basal medium. The medium was changed every 2 days. Protein was extracted on day 4, day 7 , and day 10 with cold RIPA buffer $(50 \mathrm{mM}$ Tris $\mathrm{pH}$ 7.4, $150 \mathrm{mM} \mathrm{NaCl}, 1 \%$ triton $\mathrm{X}-100,0.1 \%$ SDS, $1 \%$ sodium deoxycholate, $5 \mathrm{mM}$ EDTA, $30 \mathrm{mM} \mathrm{Na}_{2} \mathrm{HPO}_{4}$, and $50 \mathrm{mM}$ $\mathrm{NaF}$ ). SH-SY5Y cells were immediately scraped off followed by centrifugation at $12,000 \mathrm{rpm}$ for 15 minutes at $4^{\circ} \mathrm{C}$. The supernatants were collected and protein concentrations were determined using Bradford reagent (Bio-Rad Laboratories, USA) by measuring absorbance at $595 \mathrm{~nm}$. Equal amount of the protein was loaded onto $12.5 \%$ SDS-PAGE with a total volume of $20 \mu \mathrm{L} /$ well. The protein from the acrylamide gel was transferred to a nitrocellulose membrane. The membrane was blocked with skim milk in TBS-T at $4^{\circ} \mathrm{C}$ overnight and then incubated with primary rabbit polyclonal antibody to TH (1:1000 dilution; Cell Signal Technology) overnight. Subsequently, the membrane was incubated with horseradish peroxidase-conjugated goat anti-rabbit secondary antibody (1:5000 dilution) for 45 minutes at room temperature. Band intensity was determined using chemiluminescent (ECL) reagents (Pierce, USA) and analyzed on Image-J software (National Institutes of Health, Bethesda, MD, USA).

2.4. Immunostaining for Tyrosine Hydroxylase. SH-SY5Y cells were plated on $12 \mathrm{~mm}$ poly-L-lysine/laminin-coated coverslips at a density of $1 \times 10^{4}$ cells/coverslip. Cells were treated with $10 \mu \mathrm{M}$ of RA for 4 and 7 days. Cells were then fixed in $4 \%$ paraformaldehyde for 15 minutes at room temperature followed by sequential incubation with permeabilizing solution $(0.2 \%$ Triton $\mathrm{X}-100)$ in PBS for 30 minutes at room temperature. Then, cultures were washed again with PBS and incubated in blocking solution (3\% BSA in $0.5 \%$ Tween 20 in PBS) for 30 minutes. Cells were incubated with rabbit polyclonal antibody against TH (1:200 dilution in blocking solution; Merck Millipore AB152) overnight at $4^{\circ} \mathrm{C}$. After washing, cells were incubated with 1:500 dilution of Alexa 488-conjugate secondary antibody for 1 hour at room temperature. Coverslips were then mounted with Vectashield antifading mounting medium with DAPI (Vector Laboratories, CA). Cells were visualized under a confocal laser-scanning microscope (Olympus Model FV 1000, Tokyo, Japan).

2.5. Staining for Nuclear DNA. SY5Y cells were seeded on coverslips at density of $6 \times 10^{4}$ cells/coverslip. For undifferentiated cells, cells were treated with $500 \mu \mathrm{M} \mathrm{MPP}{ }^{+}$for 24 hours. For differentiated cells, 3-day treatment of $10 \mu \mathrm{M}$ RA was used for differentiation, and cells were treated with $1000 \mu \mathrm{M} \mathrm{MPP}^{+}$for 24 hours. Cells were washed, fixed with $4 \%$ paraformaldehyde for 30 minutes at room temperature, and washed with PBS. Cells were stained with Hoechst 33258 in PBS for 20 minutes at room temperature and then washed again. Coverslips were then mounted in 50\% glycerol containing $20 \mathrm{mM}$ citric acid and $50 \mathrm{mM}$ orthophosphate. Nuclear morphology was visualized under a laser scanning confocal microscopy (Olympus FV1000, Olympus, Tokyo, Japan) with excitation wavelength $556 \mathrm{~nm}$ and emission wavelength $573 \mathrm{~nm}$. 
2.6. Real-Time Quantitative RT-PCR Analysis. Total mRNA was extracted from SH-SY5Y cells using PARIS kit according to the manufacturer's instructions. The quantity and purity of RNA were determined by optical density measurements at OD A260/A280 ratio with 1.8 or above using Nanodrop 2000 spectrophotometer (Thermo Fisher Scientific Inc., Wilmington, DE, USA). The cDNA was synthesized from $1 \mu \mathrm{g}$ of RNA using Masterscript RT-PCR System (5 PRIME, Gaithersburg, MD, USA), according to the manufacturer's instructions, and stored at $-20^{\circ} \mathrm{C}$ until assay. KAPA SYBR FAST qPCR kit (Kapa Biosystems, Woburn, MA, USA) was used for real-time PCR quantification. The $20 \mu \mathrm{L}$ real-time PCR reaction mixture contained $20 \mathrm{ng}$ cDNA template, $10 \mu \mathrm{L}$ of $1 \mathrm{x}$ KAPA SYBR FAST qPCR master mix, $200 \mathrm{nM}$ of forward and reverse primers, and PCR-grade water. $\beta$-actin was used as a reference gene. The sequences of the primers for the RT-PCR were as follows: $\mathrm{p} 53$ : sense, $5^{\prime}$ GGAGGTTGTGAGGCGCTGG-3' ${ }^{\prime}$; antisense, $5^{\prime}$-CACGCACCTCAAAGCTGTTC-3'; Bax: sense, $5^{\prime}$-CCCGAGAGGTCTTTTTCCGAG- ${ }^{\prime}$; antisense, $5^{\prime}$-CCAGCCCATGATGGTTCTGAT-3'; Bcl-2: sense, $5^{\prime}$-CATGTGTGTGGAGAGCGTCAA-3'; antisense, 5'-GCCGGTTCAGGTACTCAGTCA-3'; caspase- 3 : sense, $5^{\prime}$-ATGGAGAACACTGAAAACTCA- $3^{\prime}$; antisense, $5^{\prime}$-TTAGTGATAAAAATAGAGTTC- ${ }^{\prime}$; and $\beta$-actin: sense, $5^{\prime}$-TGCAGAGGATGATTGCTGAC- $3^{\prime}$; antisense, $5^{\prime}$-GAGGACTCCAGCCACAAAGA- $3^{\prime}$. The reaction was performed in the Applied Biosystems 7500 RealTime PCR System (Applied Biosystems, Foster City, CA, USA) with the PCR cycling conditions as follows: 3-minute enzyme activation at $95^{\circ} \mathrm{C}, 40$ cycles of 3 -second initial denaturation at $95^{\circ} \mathrm{C}$, and annealing/extension at $58^{\circ} \mathrm{C}$ for 32 seconds. Melting curve analysis was performed for verifying specificity of each primer after PCR to ensure amplification specificity. The threshold cycle $(\mathrm{Ct})$ number was determined and used in the comparative $\mathrm{Ct}$ method. The relative quantity of the target gene was estimated by the $2^{-\Delta \Delta \mathrm{Ct}}$ method. All data were analyzed by the ABI 7500 software, version 2.0.

2.7. Statistical Analysis. Experiments on cell viability assay, western blotting, and real-time quantitative PCR were repeated three times in triplicate measurement. Statistical analyses were performed with one-way ANOVA test followed by a post hoc analysis (Tukey's multiple comparison test) using GraphPad Prism 5 Software for Windows (GraphPad Software, Inc., San Diego, CA, USA). The results were expressed by mean \pm standard error of the mean (mean \pm SEM) for each group. A $P$ valueless than 0.05 was regarded as statistically significant.

\section{Results}

3.1. Proliferation Rate of Undifferentiated and RA-Differentiated SH-SY5Y Cells. To study the effects of RA on the proliferation of SH-SY5Y cells, an MTT assay was performed to measure cell numbers. The MTT assay involves the use of mitochondrial activity in live cells to convert MTT to formazan, the concentration of which can be measured spectrophotometrically. The reduction of tetrazolium salts by metabolically

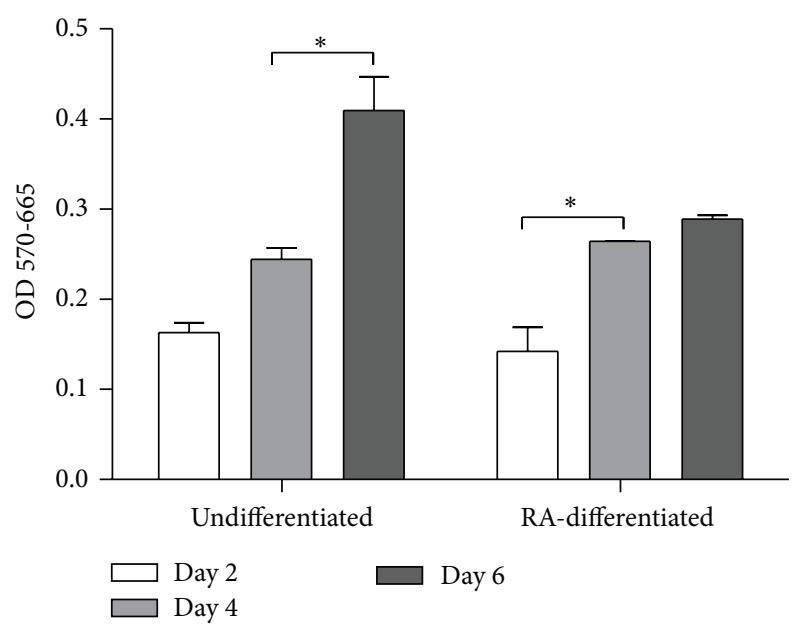

FIGURE 1: The proliferation of undifferentiated and differentiated SH-SY5Y cells. Cells were differentiated in $10 \mu \mathrm{M}$ retinoic acid (RA). After differentiation for 2, 4, and 6 days, cell proliferation was assessed using MTT assay. Absorbance at $570 \mathrm{~nm}$ with $665 \mathrm{~nm}$ as a reference was measured, and differences between the two absorbances were analyzed. Data are expressed as mean \pm SD from three replicate wells. ${ }^{*} P<0.05$.

active cells in the MTT assay is now widely accepted as a reliable way to examine cell proliferation. Absorbance values that are lower than the control cells indicate a reduction in the rate of cell proliferation. Conversely, a higher absorbance rate indicates an increase in cell proliferation. Statistically significant differences $(P<0.05)$ in cell number were observed between days 4 and 6 in undifferentiated cells and between days 2 and 4 in RA-differentiated cells (Figure 1). The proliferation rate was estimated as a percentage of the OD570-665 changes from day 2 to day 4 and from day 4 to day 6 for each group. In agreement with previous studies that have shown that cells treated with $10 \mu \mathrm{M}$ RA for 5 days cease proliferating and differentiate into a neuronal phenotype [15], our results showed a decline in the cell proliferation rate from day 4 to day 6 for RA-differentiated cells. In undifferentiated cells, the proliferation rate remained high from day 4 to day 6 , compared to that from day 2 to day 4 .

3.2. Expression of Tyrosine Hydroxylase Protein in Undifferentiated and RA-Differentiated SH-SY5Y Cells. To examine the effects of RA on changes in neuronal phenotypes, the expression of a dopaminergic neuronal marker tyrosine hydroxylase was evaluated in undifferentiated and RA-differentiated cells by the western blot immunoassay. A significant, gradual increase in $\mathrm{TH}$ protein content was observed in RAdifferentiated cells from day 4 of differentiation to day 7 and day $10(P<0.001$ for all comparisons; Figure 2(b)). In undifferentiated cells, the expression of $\mathrm{TH}$ protein was gradually decreased, significantly, from day 4 to day 7 and day 10 (Figure 2(a)). Based on these data, the expression of $\mathrm{TH}$ protein was reevaluated through immunostaining in undifferentiated cells and 4- and 7-day RA-differentiated cells (Figure 2(c)). The result confirmed a gradual increase in TH 


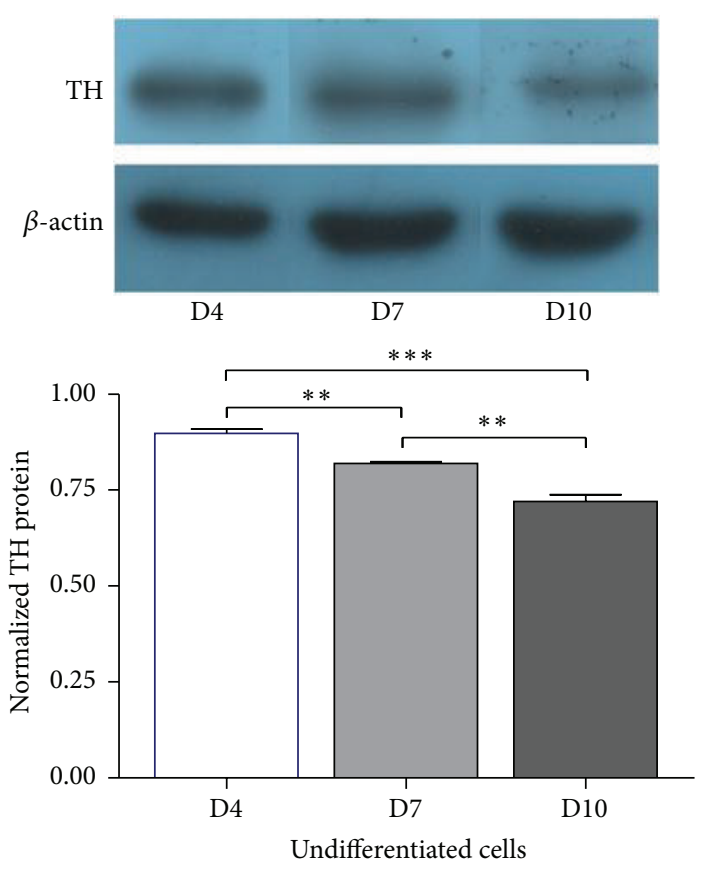

(a)

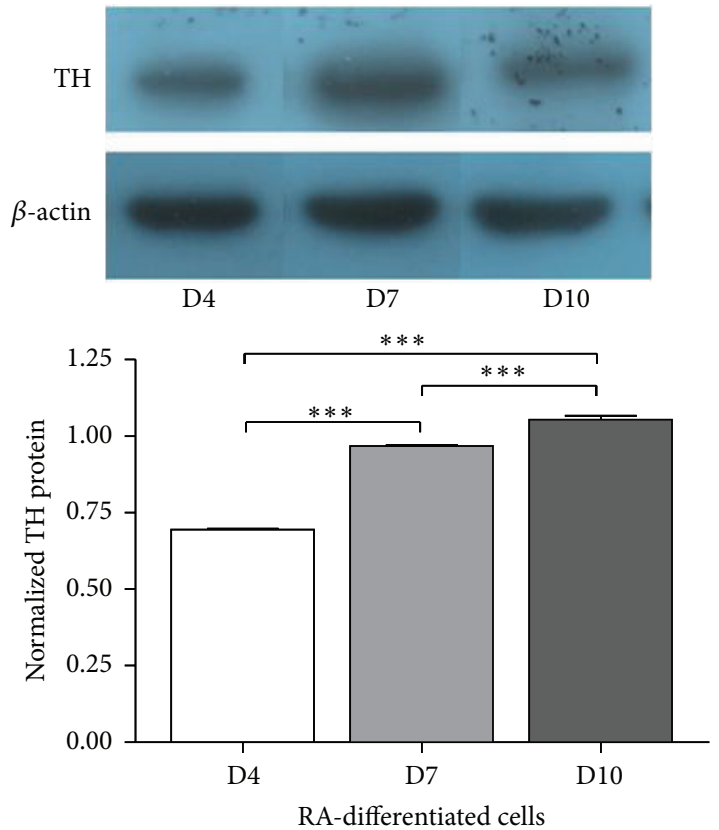

(b)

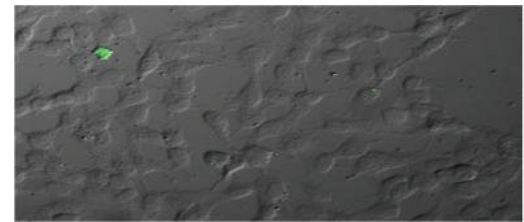

Undifferentiated (D4)

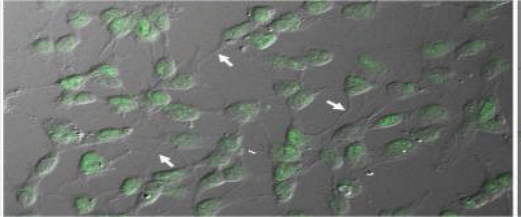

RA-differentiated (D4)

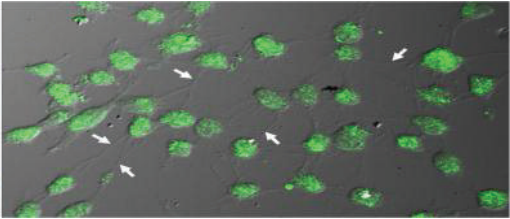

RA-differentiated (D7)

(c)

FIGURE 2: Expression of tyrosine hydroxylase in undifferentiated and differentiated SH-SY5Y cells. Cells were differentiated in 10- $\mu \mathrm{M}$ retinoic acid (RA). After differentiation for 4, 7, and 10 days, tyrosine hydroxylase (TH) was detected with western blotting (a and b). The density of bands was analyzed in comparison with that of $\beta$-actin. Data are expressed as mean \pm SEM $(n=3) .{ }^{* *} P<0.01$; ${ }^{* * *} P<0.001$. Expression of TH was visualized through immunostaining in undifferentiated cells and 4- and 7-day RA-differentiated cells (c). White arrows indicate areas of neurite outgrowth.

protein expression in differentiated SH-SY5Y cells along with the presence of neuritic outgrowth.

\subsection{Susceptibility of Undifferentiated and RA-Differentiated} SH-SY5Y Cells Exposed to MPP ${ }^{+}$. Undifferentiated and RAdifferentiated SH-SY5Y neuroblastoma cells were exposed to $125,250,500,1000$, and $2000 \mu \mathrm{M}$ of $\mathrm{MPP}^{+}$for 24 hours. For RA-differentiated cells, the cells were incubated with $10 \mu \mathrm{M}$ RA for 3 days to induce neuronal differentiation prior to exposure to the various dosages of $\mathrm{MPP}^{+}$. Cell viability was examined with an MTT assay. Significant decreases in cell viability of undifferentiated and RA-differentiated cells were observed after 24-hour exposure to $250 \mu \mathrm{M}$ of $\mathrm{MPP}^{+}$when compared to the control $(P<0.01$; Figure 3$)$, and higher dosages of $\mathrm{MPP}^{+}$led to higher numbers of cell death in both undifferentiated and RA-differentiated cells $(P<0.001)$. The different susceptibility of undifferentiated and RA-differentiated cells to $\mathrm{MPP}^{+}$was observed at an $\mathrm{MPP}^{+}$dosage of $500 \mu \mathrm{M}$ compared to untreated cells, and, after RA-differentiation, an MTT assay showed a 0.1-fold increase $(P<0.05)$ in the number of viable cells compared to undifferentiated cells 24 hours after exposure to $\mathrm{MPP}^{+}$. It is noteworthy that a decrease in cell viability to approximately $50 \%\left(\mathrm{IC}_{50}\right)$ required $500 \mu \mathrm{M}$ and $1000 \mu \mathrm{M}$ of $\mathrm{MPP}^{+}$for undifferentiated and RA-differentiated cells, respectively. These dosages of $\mathrm{MPP}^{+}$were used to treat undifferentiated and RA-differentiated cells in further experiments.

Nuclear morphology of undifferentiated and RAdifferentiated cells was further examined using Hoechst 33258 staining after exposure of the cells to 500 and $1000 \mu \mathrm{M}$ $\mathrm{MPP}^{+}$for 24 hours, respectively. After treatment with 500 $\mathrm{MPP}^{+}$, undifferentiated cells showed distinct morphological changes typical of apoptosis, such as chromatin condensation and nuclear fragmentation (Figure 4(b)). Similar changes in nuclear morphology were also observed in RA-differentiated cells treated with $1000 \mu \mathrm{M} \mathrm{MPP}{ }^{+}$(Figure 4(d)). Apoptotic nuclei were significantly observed in $\mathrm{MPP}^{+}$-treated undifferentiated cells $(P<0.001$; Figures $4(\mathrm{e})$ and $4(\mathrm{f}))$. It is worth noting that the degree of apoptotic nuclei observed in Hoechst staining did not correspond to the degree of 

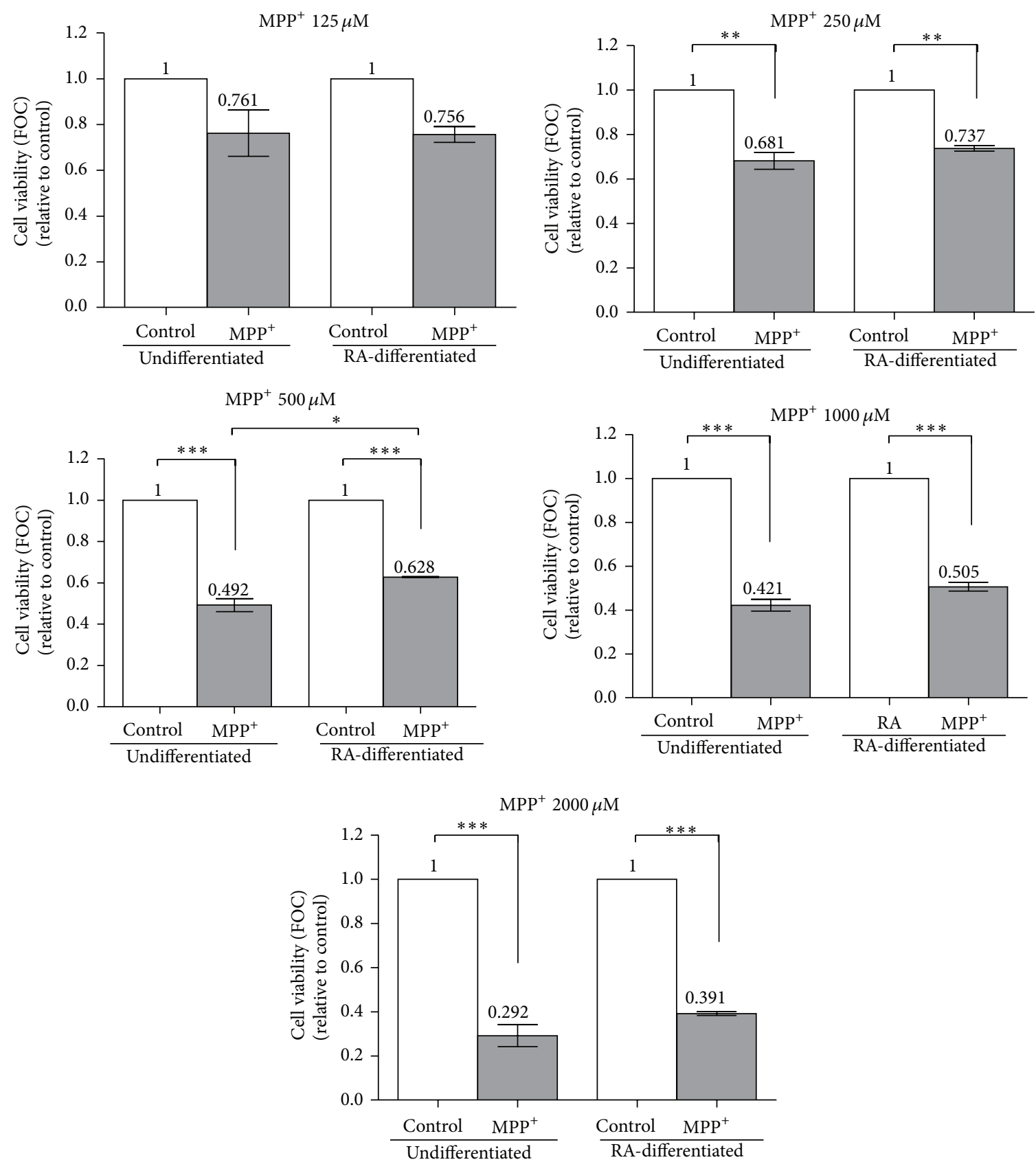

FIGURE 3: Effect of $\mathrm{MPP}^{+}$on cell viability of undifferentiated and differentiated SH-SY5Y cells. Cells were differentiated in $10-\mu \mathrm{M}$ retinoic acid (RA) for 3 days. Undifferentiated and RA-differentiated cells were plated at the same time and exposed to 125, 250, 500, 1000, and 2000 $\mu \mathrm{M}$ of $\mathrm{MPP}^{+}$for 24 hours. Cell viability was examined using MTT assay. Data are expressed as fold of changes (FOC; mean \pm SEM), relative to control $(n=3) .{ }^{*} P<0.05 ;{ }^{* *} P<0.01$; and ${ }^{* * *} P<0.001$.

cell death observed in the MTT assay (Figure 3). More detailed studies are required to examine this apparent irrelevance. Given our culture conditions being constant and chemicals preparation being unchanged, one hypothesis is that the MTT assay may detect changes in the number of metabolically active cells, which occur earlier than changes in DNA morphology.
3.4. Expression of Apoptosis-Related Genes in Undifferentiated and RA-Differentiated SH-SY5Y after Treatment with MPP . To observe the expression of apoptosis-related genes in $\mathrm{SH}-$ SY5Y cells that were exposed to $\mathrm{IC}_{50}$ dosages of $\mathrm{MPP}^{+}$, the genes $\mathrm{Bax}, \mathrm{Bcl}-2$, p53, and caspase- 3 were tested using quantitative real-time RT-PCR analyses of 24-hour incubation of undifferentiated and RA-differentiated cells in $500 \mu \mathrm{M}$ and 


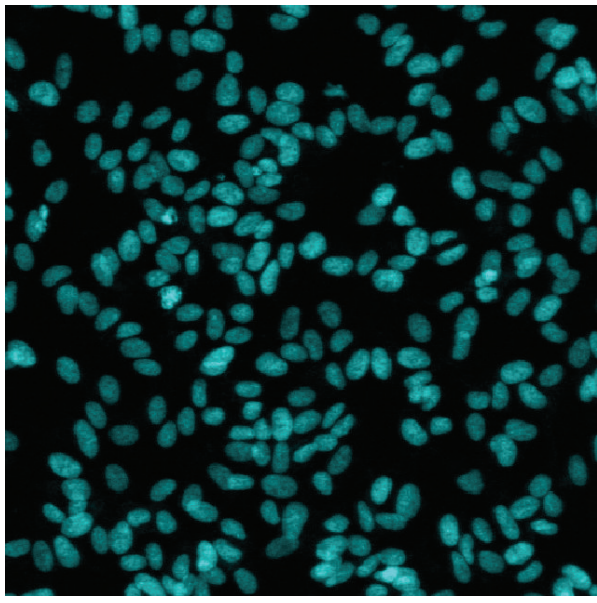

Undifferentiated

(a)

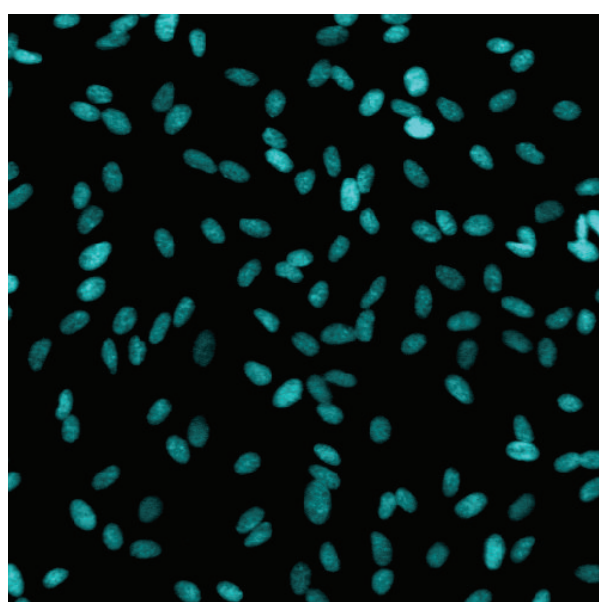

RA-differentiated

(c)

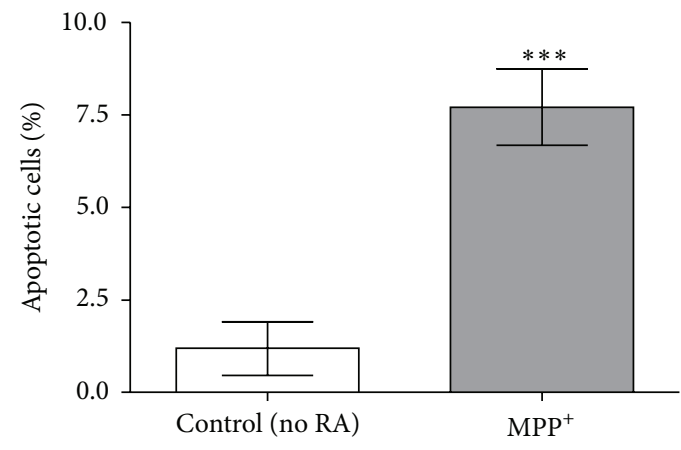

(e)

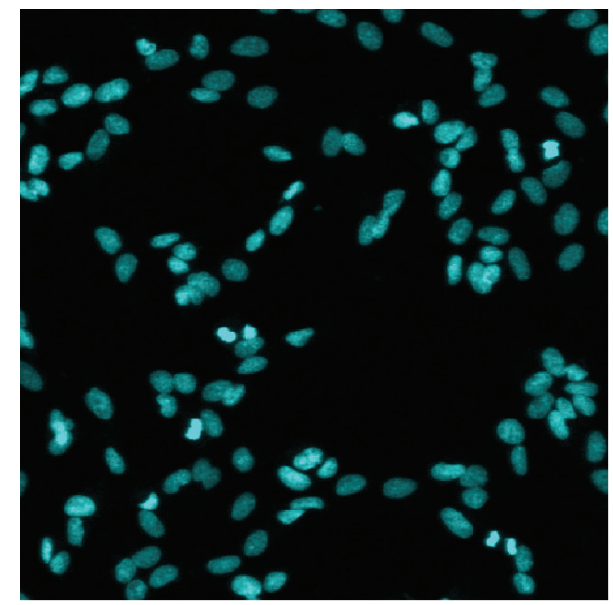

Undifferentiated $+\mathrm{MPP}^{+}$

(b)

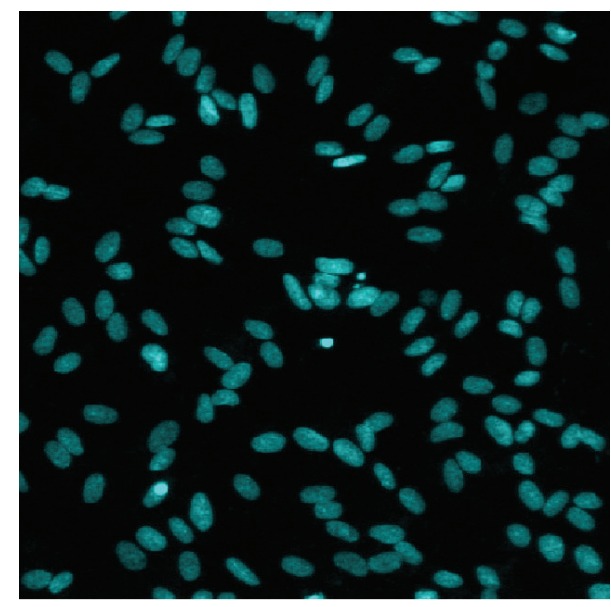

RA-differentiated $+\mathrm{MPP}^{+}$

(d)

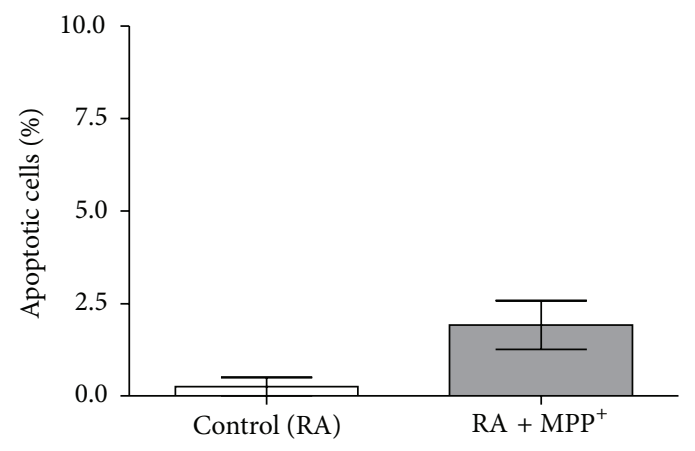

(f)

Figure 4: Effect of $\mathrm{MPP}^{+}$on nuclear morphology in undifferentiated and differentiated SH-SY5Y cells. Cells were undifferentiated (a and b) and were differentiated in 10- $\mu \mathrm{M}$ retinoic acid (RA) for 3 days (c and d). Undifferentiated (b) and differentiated cells (d) were exposed to 500 and $1000 \mu \mathrm{M}$ of $\mathrm{MPP}^{+}$for 24 hours, respectively. Apoptotic nuclear morphology was visualized by DNA staining with Hoechst 33258 . Percentage of cells with apoptotic nuclei was calculated (e and f). Data are expressed as mean \pm SEM $(n=3)$ of percentage to untreated cells. ${ }^{* * *} P<0.001$. 


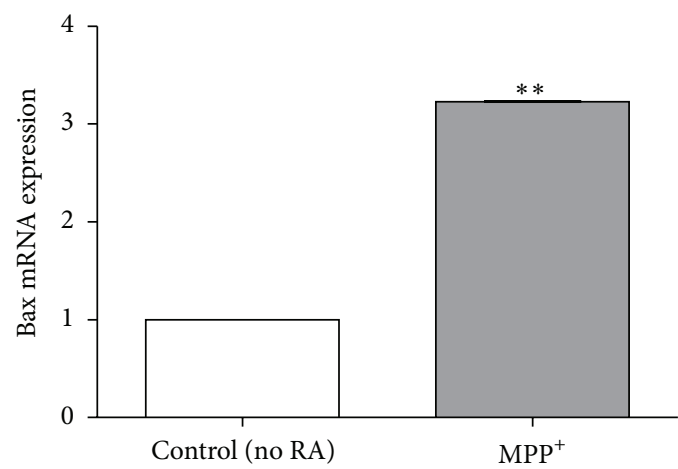

(a)

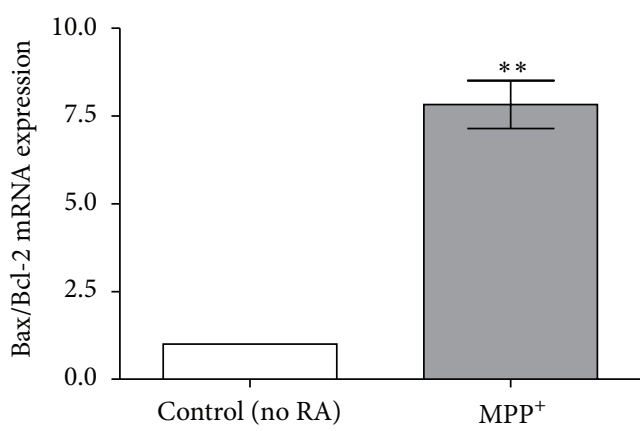

(c)

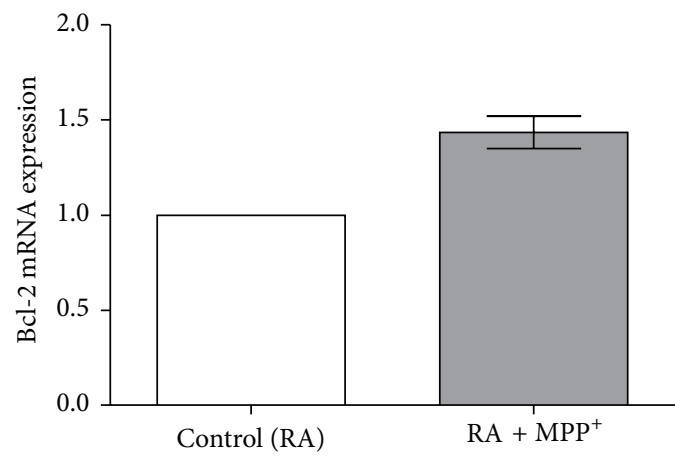

(e)

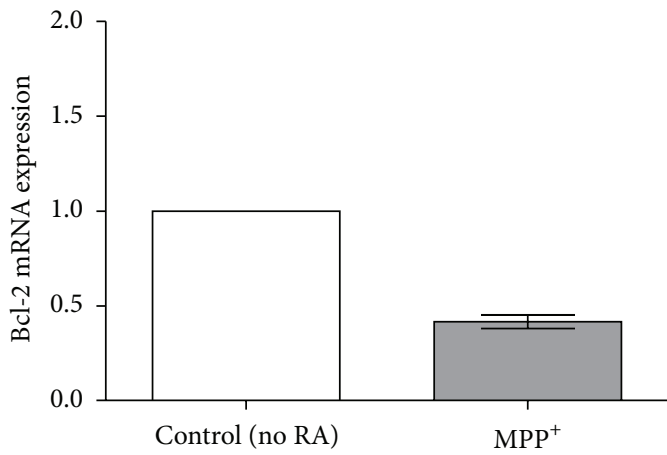

(b)

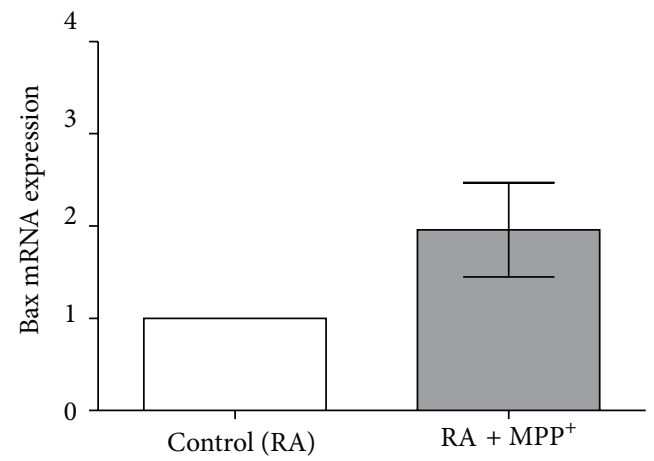

(d)

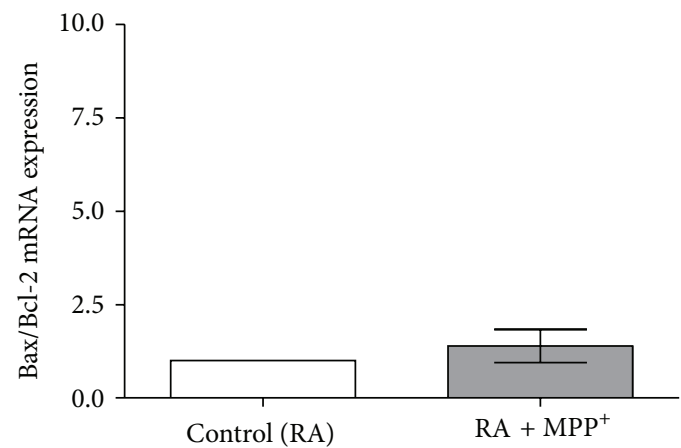

(f)

FiguRE 5: Effect of $\mathrm{MPP}^{+}$on Bax and Bcl-2 mRNA expression in undifferentiated and differentiated SH-SY5Y cells. Cells were differentiated in $10-\mu \mathrm{M}$ retinoic acid (RA) for 3 days. Undifferentiated (a-c) and differentiated cells (d-f) were exposed to 500 and $1000 \mu \mathrm{M}$ of $\mathrm{MPP}^{+}$for 24 hours, respectively. Expression of Bax mRNA ( $a$ and d), Bcl-2 mRNA (b and e), and Bax/Bcl-2 ratio (c and f) was analyzed with quantitative real-time RT-PCR, relatively compared to their respective untreated controls. The expression levels of the target gene were normalized to the expression level of $\beta$-actin. Data are expressed as mean $\pm \operatorname{SEM}(n=3) .{ }^{* *} P<0.01$.

$1000 \mu \mathrm{M} \mathrm{MPP}^{+}$, respectively. As Bax was increased by $\mathrm{MPP}^{+}$ whereas $\mathrm{Bcl}-2$ was not, the $\mathrm{Bax} / \mathrm{Bcl}-2$ ratio was significantly increased by $\mathrm{MPP}^{+}$in undifferentiated cells $(P<0.01$; Figures 5(a)-5(c)). In RA-differentiated cells, both Bax and $\mathrm{Bcl}-2$ were increased, leading to an insignificant change in the Bax/Bcl-2 ratio (Figures 5(d)-5(f)). An upstream regulation of Bax and Bcl-2 was then investigated. The expression of p53 mRNA was significantly increased in undifferentiated cells after 24-hour exposure to $500 \mu \mathrm{M} \mathrm{MPP}^{+}$when compared to the unexposed control $(P<0.05$; Figure $6(\mathrm{a}))$, whereas it was not significantly increased in RA-differentiated cells exposed to $1000 \mu \mathrm{M} \mathrm{MPP}^{+}$(Figure 6(b)). Finally, the effect of $\mathrm{MPP}^{+}$ on the expression of caspase- 3 mRNA, a critical executioner of apoptosis, was investigated. The expression of caspase- 3 mRNA was significantly increased in undifferentiated cells treated with $500 \mu \mathrm{M} \mathrm{MPP}{ }^{+}$for 24 hours when compared to the unexposed control $(P<0.01$; Figure 6(c)), whereas it was not significantly increased in RA-differentiated cells treated with $1000 \mu \mathrm{M} \mathrm{MPP}^{+}$(Figure 6(d)).

\section{Discussion}

The human neuroblastoma SH-SY5Y cell line has been widely used in $\mathrm{PD}$ research. The question of whether 


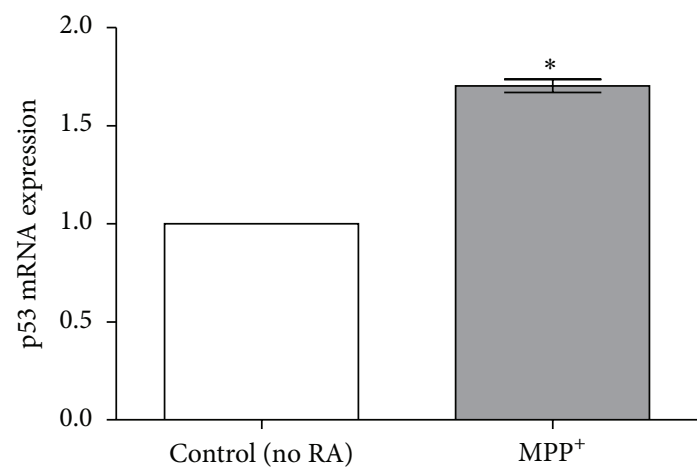

(a)

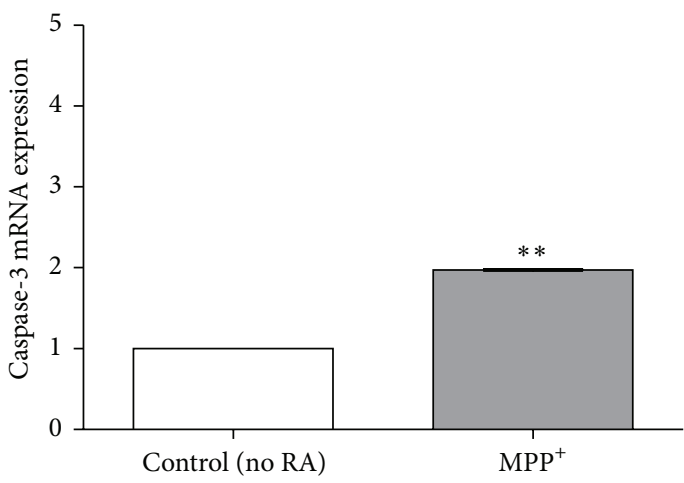

(c)

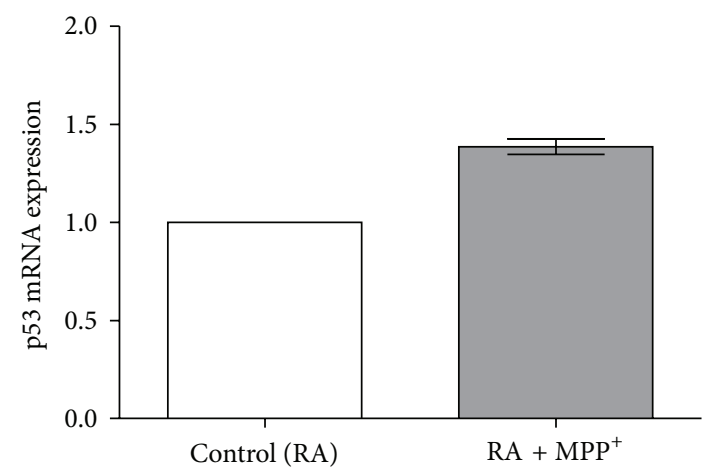

(b)

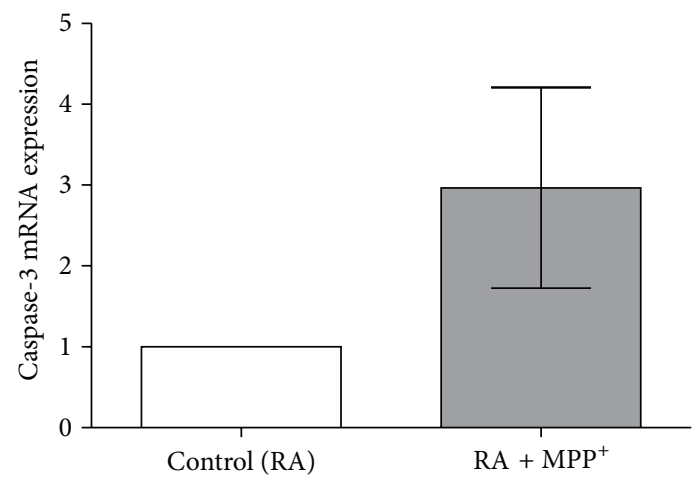

(d)

Figure 6: Effect of $\mathrm{MPP}^{+}$on p53 and caspase-3 mRNA expression in undifferentiated and differentiated SH-SY5Y cells. Cells were differentiated in 10- $\mu \mathrm{M}$ retinoic acid (RA) for 3 days. Undifferentiated (a and c) and differentiated cells (b and d) were exposed to 500 and $1000 \mu \mathrm{M}$ of $\mathrm{MPP}^{+}$for 24 hours, respectively. Expression of p53 mRNA (a and b) and caspase-3 (c and d) was analyzed with quantitative real-time RT-PCR, relatively compared to their respective untreated controls. The expression levels of the target gene were normalized to the expression level of $\beta$-actin. Data are expressed as mean $\pm \operatorname{SEM}(n=3) .{ }^{*} P<0.05 ;{ }^{* *} P<0.01$.

undifferentiated or differentiated SH-SY5Y cells are more suitable remains controversial. The differentiated phenotype of SH-SY5Y cells is claimed to be more appropriate due to expressing desired morphological and biochemical characteristics similar to dopaminergic neurons and its lack of oncogenic and mitogenic properties [3]. However, changes in the dopaminergic properties of differentiated cells were found not to be significant compared to undifferentiated cells, and use of RA as an inducing agent may modulate the Akt prosurvival pathway leading to a higher tolerance to neurotoxin toxicity [2].

To address this unresolved issue, the differential expression of a specific marker of dopaminergic neurons and the differential response in the expression of apoptosis-related genes to a neurotoxin $\mathrm{MPP}^{+}$in undifferentiated and RAdifferentiated SH-SY5Y cells were assessed. First, the expression of TH protein could be detected in undifferentiated cells, and the expression was gradually decreased in relation to the longer culture duration, whereas the expression of $\mathrm{TH}$ protein was gradually increased in RA-differentiated cells from day 4 to at least day 10. Second, undifferentiated cells required a lower $\mathrm{MPP}^{+}$dosage $(500 \mu \mathrm{M})$ than RA-differentiated cells $(1000 \mu \mathrm{M})$ to cause a $50 \%$ cell death, and apoptotic nuclei could be more significantly observed in $500-\mu \mathrm{M}$
$\mathrm{MPP}^{+}$-treated undifferentiated cells than in the 1000$\mu \mathrm{M} \mathrm{MPP}{ }^{+}$-treated differentiated cells, compared to their untreated controls. Lastly, treatment with $500 \mu \mathrm{M} \mathrm{MPP}$ led to significant increases in the $\mathrm{Bax} / \mathrm{Bcl}-2$ ratio, $\mathrm{p} 53$, and caspase- 3 mRNA expression in undifferentiated cells, whereas a significant increase was not observed in differentiated cells treated with $1000 \mu \mathrm{M} \mathrm{MPP}^{+}$. In our study on cell susceptibility to $\mathrm{MPP}^{+}$and the expression of apoptosisrelated genes, a 3-day duration of $10 \mu \mathrm{M}$ RA exposure was used to induce SH-SY5Y cells for neuronal differentiation, which is based on our observations and those of other studies showing that TH expression and neurite outgrowth can be observed at this early period (Figures 2(b) and 2(c)) [16-19].

The results of cell susceptibility to $\mathrm{MPP}^{+}$and the level of expression of apoptosis-related genes suggested that differentiated cells are more resistant to the effects of $\mathrm{MPP}^{+}$. Cheung et al. [2] showed that RA-differentiated cells also expressed higher tolerance, as shown by the lower rate of the release of $\mathrm{LDH}$, cell mortality, and caspase- 3 activation when compared to undifferentiated cells. However, Lopes et al. [3] showed that SH-SY5Y cells become significantly more sensitive to a toxin during the differentiation process as shown by cell mortality assay and $\mathrm{GI}_{50}$ values of the toxin. In general, a cell line with more sensitivity to toxin is regarded 
as being suitable for the investigation of a toxin mechanism or disease pathogenesis. Both studies by Cheung et al. and Lopes et al. showed contrasting results in the vulnerability for differentiated SH-SY5Y cells to toxins. There is no data on differences in cell susceptibility to neurotoxins between undifferentiated SH-SY5Y cells, RA-differentiated cells, and primary dopaminergic mesencephalic neurons. The higher tolerance of RA-differentiated SH-SY5Y cells to neurotoxins may be explained by the role of RA in the activation of the Akt prosurvival pathway [2]. In the brain, neurotrophic factors secreted from surrounding astrocytes can promote neuronal survival and differentiation. Neurotrophic factors can activate Akt signaling in neurons. Thus, RA-induced Akt activation may mimic the astrocyte environment that surrounds neurons in the brain, thereby increasing the validity of the differentiated SH-SY5Y cell model.

The results on the positive expression of $\mathrm{TH}$ protein using western blot analysis and immunostaining in undifferentiated SH-SY5Y cells are relevant with Cheung et al. [2], while Lopes et al. showed undetectable or very low levels of TH expression [3]. Both Cheung et al. and Lopes et al. measured TH immunocontent in undifferentiated cells at about 7 days after plating. After RA treatment, Lopes et al. found a significant increase in TH expression in differentiated cells at days 4, 7, and 10 similar to our results (Figure 2(b)) whereas Cheung et al. measured the expression at day 7 and did not find any increment. These discrepancies may reflect the uneven dynamics of $\mathrm{TH}$ protein translation in both proliferating undifferentiated cells and differentiated cells, which may be influenced by various conditions such as the differences in culture media used, which in Lopes et al. was DMEM/Ham's F12, in Cheung et al. was MEM, and in this study was MEM/Ham's F12. Greater amounts of amino acids, vitamins, and other substances in Ham's F12 may affect SH-SY5Y cell growth and differentiation [20]. Although TH expression can be found in undifferentiated cells, these cells do not secrete dopamine [21]. TH becomes active in RA-differentiated cells and these cells have a dopaminergic-like phenotype [1]. These data imply that considering whether undifferentiated or differentiated SH-SY5Y cells are suitable as a cellular model of PD based exclusively on the data of TH expression levels shown in various studies may not be a proper approach.

A previous study showed that significant cell death of RAdifferentiated cells was observed after 24 hours of exposure to 500 and $1000 \mu \mathrm{M} \mathrm{MPP}^{+}$, and there was no apparent increase in the cell death by extending the exposure period to 48 hours [22]. For undifferentiated cells, studies showed that cell viability decreased to approximately $50 \%$ when cells were treated with $500 \mu \mathrm{M} \mathrm{MPP}^{+}$for 24 hours $[7,23,24]$. Similarly, we observed significant cell death after 24-hour exposure of RA-differentiated cells as well as of undifferentiated cells to $250,500,1000$, and $2000 \mu \mathrm{M} \mathrm{MPP}^{+}$. Higher $\mathrm{IC}_{50}$ of $\mathrm{MPP}^{+}$in RA-differentiated cells as shown in this study may indicate that their tolerance to $\mathrm{MPP}^{+}$toxicity is higher than that of undifferentiated cells. Thus, we further examined the expression of Bax, Bcl-2, p53, and caspase-3 mRNAs to reaffirm changes in cell susceptibility to $\mathrm{MPP}^{+}$-induced neurotoxicity. Although increases in the $\mathrm{Bax} / \mathrm{Bcl}-2$ ratio, $\mathrm{p} 53$, and caspase3 expression were observed in both $500 \mu \mathrm{M} \mathrm{MPP}^{+}$-treated undifferentiated and $1000 \mu \mathrm{M} \mathrm{MPP}{ }^{+}$-treated differentiated cells compared to their own controls, significant increases were also apparently shown in undifferentiated cells. Lower susceptibility of RA-differentiated SH-SY5Y cells to $1000 \mu \mathrm{M}$ $\mathrm{MPP}^{+}$and $25 \mu \mathrm{M}$ 6-OHDA has been demonstrated in a previous study based on the measurement of LDH release, cell viability, and caspase-3 activity in SH-SY5Y cells after RA-differentiation for 7 days [2]. However, our results suggest that the higher tolerance of RA-differentiated cells to $1000 \mu \mathrm{M} \mathrm{MPP}^{+}$can be observed as early as 3 days of RAdifferentiation.

Higher tolerance of RA-differentiated SH-SY5Y cells to $\mathrm{MPP}^{+}$and 6-OHDA may be explained by the role of RA in the activation of the Akt prosurvival pathway [2]. Although it has been stated that neuroblastoma cells have to be differentiated for at least 7 days for experimentation [25], there is no evidence showing changes of cell susceptibility to neurotoxins when comparing between shorter and longer durations for differentiation. There is also no data on differences in cell susceptibility to neurotoxins between RA-differentiated SH-SY5Y cells and primary dopaminergic mesencephalic neurons. With the lack of these data, one might raise the question of what length of time of RA-induced differentiation would be appropriate to make differentiated cells mimic primary dopaminergic neurons. Prolonged RA treatment of SH-SY5Y cells for 14 days can lead to an increase in dopamine transporter protein (DAT) expression [26], which may result in increased sensitivity of RA-differentiated cells to $\mathrm{MPP}^{+}$. $\mathrm{MPP}^{+}$toxicity enhanced by overexpression of DAT has been reported in Drosophila dopaminergic neurons [27]. Thus, if prolonged RA treatment leads to increased DAT activity beyond the basal activity of primary dopaminergic neurons, a shorter duration of RA treatment may be appropriate to induce SH-SY5Y cells for a dopaminergic model of PD.

In addition to the role of RA in the Akt activation, the number of mitochondria in differentiated SH-SY5Y cells may be a predisposing factor to toxin susceptibility. Indirect evidence may shed light on the effect of differentiation on the mitochondrial number in SH-SY5Y cells. An average number of mitochondria, 10-22 per cell, has been measured in undifferentiated SH-SY5Y cells [28]. A study of primary hippocampal neurons showed that the number of mitochondria increases during BDNF-induced differentiation and maturation [29]. In SH-SY5Y cells, BDNF responsiveness can be induced by RA [30]. Based on this evidence, it is possible that increased numbers of mitochondria in differentiated cells could make the cells less susceptible to $\mathrm{MPP}^{+}$toxicity if we assume that the number of mitochondria could be increased in SH-SY5Y cells upon RA-differentiation. To date, there is no study on the difference in the number of mitochondria between undifferentiated and differentiated SH-SY5Y cells.

SH-SY5Y neuroblastoma cells are a useful model for studying the behavior of catecholaminergic (nondifferentiated) or dopaminergic (differentiated) neurons. However, they do not mimic the behavior of primary dopaminergic neurons; they are essentially oncogenic cells and may be used with all inherent limitations. 


\section{Conclusion}

Selecting between undifferentiated and differentiated $\mathrm{SH}$ SY5Y neuroblastoma cells as a suitable and accessible cell model for PD research still needs further investigation. Based on our results, differentiated cells may be more suitable, and the shorter duration of RA differentiation may make the SH-SY5Y cell model more accessible. Counteraction of the opposite effect between prolonged activation of the prosurvival pathway and increased DAT expression by RA during cell differentiation remains to be investigated prior to the conclusion of prolonged RA-differentiated SH-SY5Y cells as an experimental model of primary dopaminergic neurons.

\section{Conflict of Interests}

The authors declare that there is no conflict of interests regarding the publication of this paper.

\section{Acknowledgments}

This research is carried out under the research framework of Mahidol University. This research was supported by grants from Thailand Research Fund and Mahidol University (IRG5780011 to P. Dharmasaroja) and Thailand Research Fund Royal Golden Jubilee Ph.D. Scholarship (PHD/0058/2556 to K. Khwanraj).

\section{References}

[1] J. A. Korecka, R. E. van Kesteren, E. Blaas et al., "Phenotypic characterization of retinoic acid differentiated SH-SY5Y cells by transcriptional profiling," PLoS ONE, vol. 8, no. 5, Article ID e63862, 2013.

[2] Y.-T. Cheung, W. K.-W. Lau, M.-S. Yu et al., "Effects of all-transretinoic acid on human SH-SY5Y neuroblastoma as in vitro model in neurotoxicity research," NeuroToxicology, vol. 30, no. 1, pp. 127-135, 2009.

[3] F. M. Lopes, R. Schröder, M. L. C. D. F. Júnior et al., "Comparison between proliferative and neuron-like SH-SY5Y cells as an in vitro model for Parkinson disease studies," Brain Research, vol. 1337, pp. 85-94, 2010.

[4] Y. Itano and Y. Nomura, "1-methyl-4-phenyl-pyridinium ion $\left(\mathrm{MPP}^{+}\right)$causes DNA fragmentation and increases the Bcl-2 expression in human neuroblastoma, SH-SY5Y cells, through different mechanisms," Brain Research, vol. 704, no. 2, pp. 240245, 1995.

[5] J. Dennis and J. P. Bennett Jr., "Interactions among nitric oxide and Bcl-family proteins after $\mathrm{MPP}^{+}$exposure of $\mathrm{SH}$ SY5Y neural cells I: $\mathrm{MPP}^{+}$increases mitochondrial NO and Bax protein," Journal of Neuroscience Research, vol. 72, no. 1, pp. 7688, 2003.

[6] X.-J. Wang and J.-X. Xu, "Salvianic acid A protects human neuroblastoma SH-SY5Y cells against $\mathrm{MPP}^{+}$-induced cytotoxicity," Neuroscience Research, vol. 51, no. 2, pp. 129-138, 2005.

[7] G. Zeng, T. Tang, H.-J. Wu et al., "Salvianolic acid b protects SHSY5Y neuroblastoma cells froml-methyl-4- phenylpyridiniuminduced apoptosis," Biological \& Pharmaceutical Bulletin, vol. 33, no. 8, pp. 1337-1342, 2010.
[8] A.-R. Doo, S.-N. Kim, S.-T. Kim et al., "Bee venom protects SHSY5Y human neuroblastoma cells from 1-methyl-4-phenylpyridinium-induced apoptotic cell death," Brain Research, vol. 1429, pp. 106-115, 2012.

[9] D. W. Luchtman, Q. Meng, X. Wang, D. Shao, and C. Song, "Omega-3 fatty acid eicospentaenoic acid attenuates $\mathrm{MPP}^{+}$. induced neurodegeneration in fully differentiated human $\mathrm{SH}$ SY5Y and primary mesencephalic cells," Journal of Neurochemistry, vol. 124, no. 6, pp. 855-868, 2013.

[10] Y. Wang, J. Gao, Y. Miao et al., "Pinocembrin protects SHSY5Y cells against $\mathrm{MPP}^{+}$-induced neurotoxicity through the mitochondrial apoptotic pathway," Journal of Molecular Neuroscience, vol. 53, no. 4, pp. 537-545, 2014.

[11] P. Janhom and P. Dharmasaroja, "Neuroprotective effects of $\alpha$ mangostin on $\mathrm{MPP}^{+}$-induced apoptotic cell death in neuroblastoma SH-SY5Y cells," Journal of Toxicology, vol. 2015, Article ID 919058, 11 pages, 2015.

[12] Z. Daixing, Z. Chengye, Z. Qiang, and L. Shusheng, "Upregulation of sestrin-2 expression via $\mathrm{P} 53$ protects against 1-methyl-4phenylpyridinium $\left(\mathrm{MPP}^{+}\right)$neurotoxicity," Journal of Molecular Neuroscience, vol. 51, no. 3, pp. 967-975, 2013.

[13] E. Sanz, A. Quintana, V. Battaglia et al., "Anti-apoptotic effect of Mao-B inhibitor PF9601N [N-(2-propynyl)-2-(5-benzyloxyindolyl) methylamine] is mediated by $\mathrm{p} 53$ pathway inhibition in $\mathrm{MPP}^{+}$-treated SH-SY5Y human dopaminergic cells," Journal of Neurochemistry, vol. 105, no. 6, pp. 2404-2417, 2008.

[14] J. S. Fridman and S. W. Lowe, "Control of apoptosis by p53," Oncogene, vol. 22, no. 56, pp. 9030-9040, 2003.

[15] M. Encinas, M. Iglesias, Y. Liu et al., "Sequential treatment of SH-SY5Y cells with retinoic acid and brain-derived neurotrophic factor gives rise to fully differentiated, neurotrophic factor-dependent, human neuron-like cells," Journal of Neurochemistry, vol. 75, no. 3, pp. 991-1003, 2000.

[16] T. Kume, Y. Kawato, F. Osakada et al., "Dibutyryl cyclic AMP induces differentiation of human neuroblastoma SH-SY5Y cells into a noradrenergic phenotype," Neuroscience Letters, vol. 443, no. 3, pp. 199-203, 2008.

[17] S. Dwane, E. Durack, and P. A. Kiely, "Optimising parameters for the differentiation of SH-SY5Y cells to study cell adhesion and cell migration," BMC Research Notes, vol. 6, no. 1, article 366, 2013.

[18] P. E. Lovat, H. Irving, M. Annicchiarico-Petruzzelli et al., "Apoptosis of N-type neuroblastoma cells after differentiation with 9-cis-retinoic acid and subsequent washout," Journal of the National Cancer Institute, vol. 89, no. 6, pp. 446-452, 1997.

[19] K. Grataitong and P. Dharmasaroja, "Retinoic acid attenuates cell death and reduces tyrosine hydroxylase expression in ethanol-treated human SH-SY5Y neuroblastoma cells," Journal of Neurology Research, vol. 2, no. 5, pp. 204-210, 2012.

[20] S. E. Ferguson, Z. Pallikaros, A. E. Michael, and B. A. Cooke, "The effects of different culture media, glucose, pyridine nucleotides and adenosine on the activity of $11 \beta$-hydroxysteroid dehydrogenase in rat Leydig cells," Molecular and Cellular Endocrinology, vol. 158, no. 1-2, pp. 37-44, 1999.

[21] J. L. Biedler, S. Roffler-Tarlov, M. Schachner, and L. S. Freedman, "Multiple neurotransmitter synthesis by human neuroblastoma cell lines and clones," Cancer Research, vol. 38, no. 11, pp. 37513757, 1978.

[22] J. B. Martins, M. D. L. Bastos, F. Carvalho, and J. P. Capela, "Differential effects of methyl-4-phenylpyridinium ion, rotenone, and paraquat on differentiated SH-SY5Y cells," Journal of Toxicology, vol. 2013, Article ID 347312, 10 pages, 2013. 
[23] F. Wang, U. F. Awan, Y. Wang et al., "Damage of neuroblastoma cell SH-SY5Y mediated by MPP ${ }^{+}$inhibits proliferation of T-cell leukemia Jurkat by co-culture system," International Journal of Molecular Sciences, vol. 15, no. 6, pp. 10738-10750, 2014.

[24] A. Arshad, X. Chen, Z. Cong, H. Qing, and Y. Deng, "TRPC1 protects dopaminergic SH-SY5Y cells from $\mathrm{MPP}^{+}$, salsolinol, and N-methyl-(R)-salsolinol-induced cytotoxicity," Acta Biochimica et Biophysica Sinica, vol. 46, no. 1, pp. 22-30, 2014.

[25] J.-R. Sarkanen, J. Nykky, J. Siikanen, J. Selinummi, T. Ylikomi, and T. O. Jalonen, "Cholesterol supports the retinoic acidinduced synaptic vesicle formation in differentiating human SH-SY5Y neuroblastoma cells," Journal of Neurochemistry, vol. 102, no. 6, pp. 1941-1952, 2007.

[26] R. Constantinescu, A. T. Constantinescu, H. Reichmann, and B. Janetzky, "Neuronal differentiation and long-term culture of the human neuroblastoma line SH-SY5Y," in Neuropsychiatric Disorders An Integrative Approach, vol. 72 of Journal of Neural Transmission. Supplementa, pp. 17-28, Springer, Vienna, Austria, 2007.

[27] L. Wiemerslage, B. J. Schultz, A. Ganguly, and D. Lee, "Selective degeneration of dopaminergic neurons by $\mathrm{MPP}^{+}$and its rescue by D2 autoreceptors in Drosophila primary culture," Journal of Neurochemistry, vol. 126, no. 4, pp. 529-540, 2013.

[28] A. Bolinches-Amorós, B. Mollá, D. Pla-Martín, F. Palau, and P. González-Cabo, "Mitochondrial dysfunction induced by frataxin deficiency is associated with cellular senescence and abnormal calcium metabolism," Frontiers in Cellular Neuroscience, vol. 8, article 124, 2014.

[29] A. Cheng, R. Wan, J.-L. Yang et al., "Involvement of PGC-1 $\alpha$ in the formation and maintenance of neuronal dendritic spines," Nature Communications, vol. 3, article 1250, 2012.

[30] A. Edsjö, E. Lavenius, H. Nilsson et al., "Expression of trkB in human neuroblastoma in relation to MYCN expression and retinoic acid treatment," Laboratory Investigation, vol. 83, no. 6, pp. 813-823, 2003. 


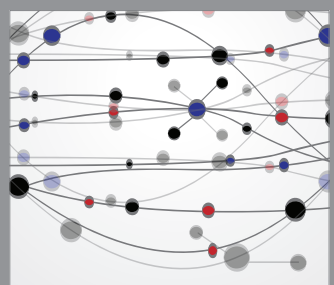

The Scientific World Journal
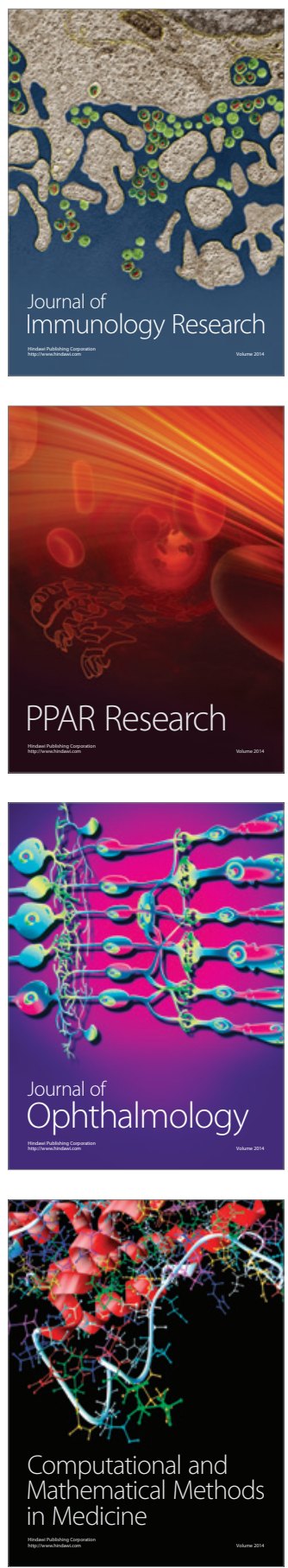

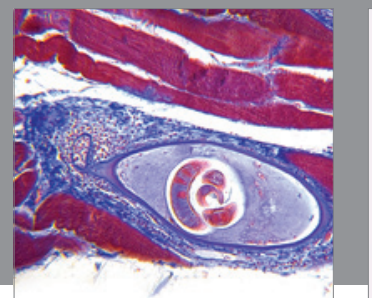

Gastroenterology

Research and Practice
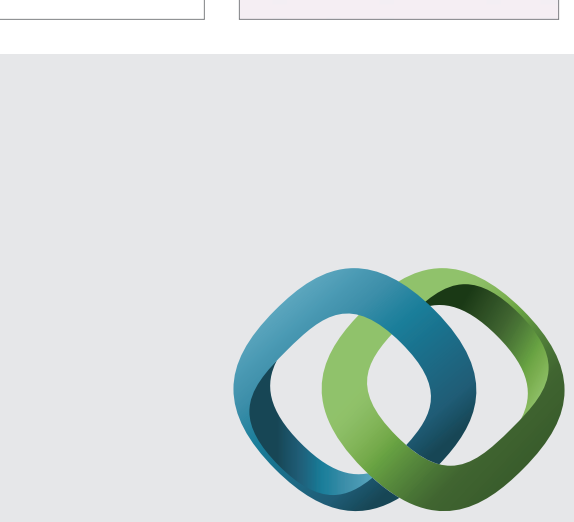

\section{Hindawi}

Submit your manuscripts at

http://www.hindawi.com
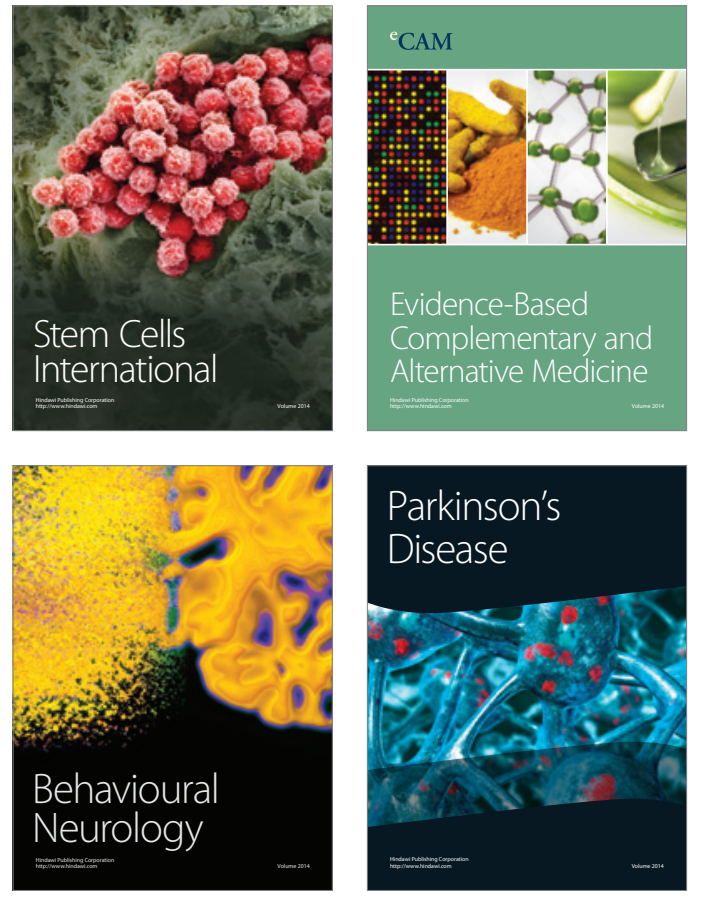
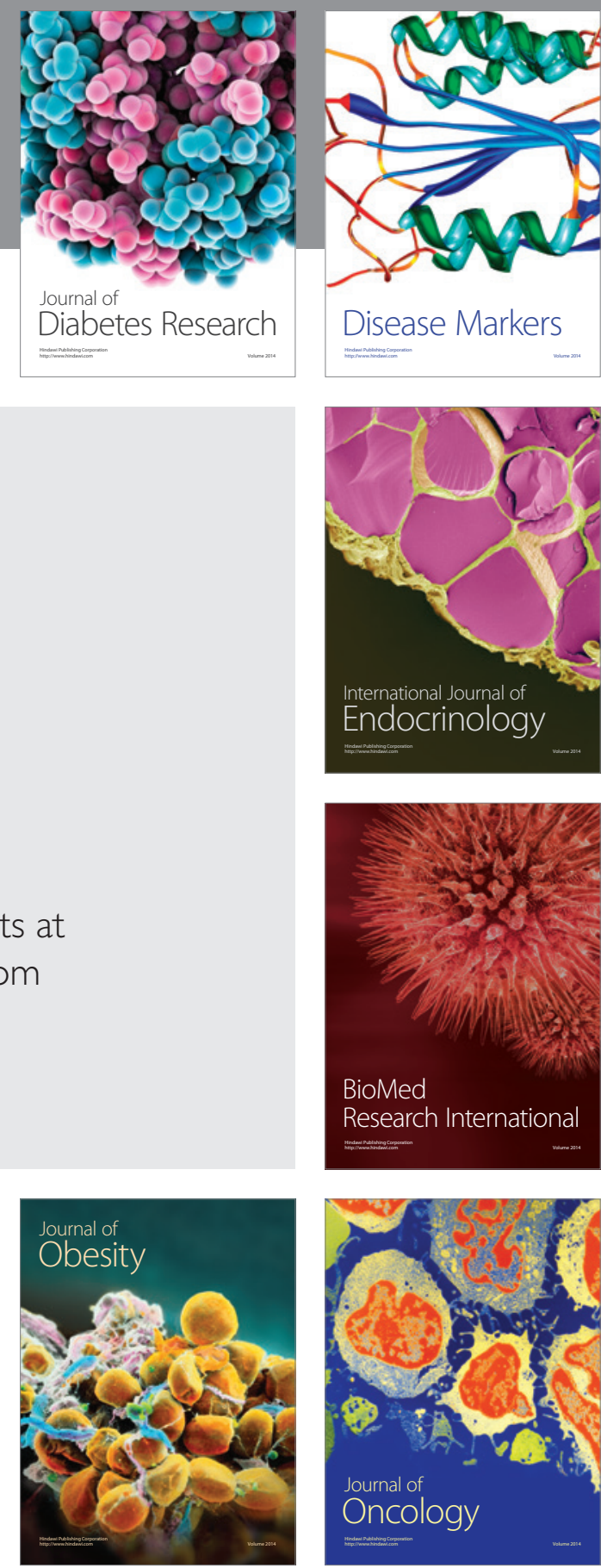

Disease Markers
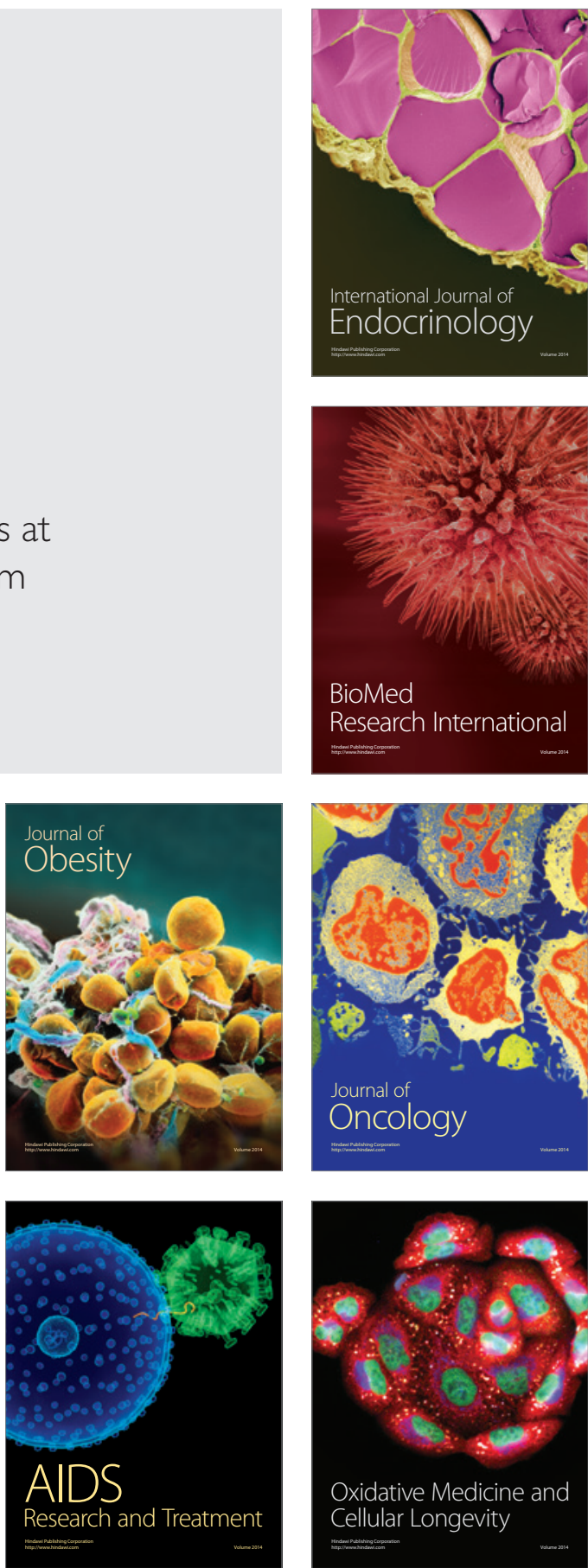